\title{
Evaluation of perinatal outcome in high-risk pregnancy at tertiary care centre
}

\author{
Anupam Rani, Urmila Karya, Sweta Kumari*
}

Department of Obstetrics and Gynecology, LLRM Medical College, Meerut, Uttar Pradesh, India

Received: 15 March 2019

Accepted: 09 April 2019

\section{*Correspondence:}

Dr. Anupam Rani,

E-mail: swepal47@gmail.com

Copyright: (C) the author(s), publisher and licensee Medip Academy. This is an open-access article distributed under the terms of the Creative Commons Attribution Non-Commercial License, which permits unrestricted non-commercial use, distribution, and reproduction in any medium, provided the original work is properly cited.

\begin{abstract}
Background: A high risk pregnancy is one in which mother, fetus or neonate is at increased risk of morbidity or mortality before or after delivery. Hence a relatively small percentage of high risk obstetric population gives rise to a disproportionately high percentage of perinatal and maternal morbidity and mortality. The perinatal outcome can be changed significantly by early detection and special intensive care to high risk pregnancies. Hence Identification of women at risk for these complicated pregnancies with poor outcome is fundamental to antenatal check-up.

Methods: 86 high risk antenatal patients attending the outpatient department and labour room were recruited after informed consent.70 normal pregnancy was taken as control group. Perinatal outcomes were compared between high risk and normal pregnancies.

Results: Adverse perinatal outcomes were more in high risk pregnancies as compared to normal pregnancies.

Conclusions: This study emphasizes on pregnancy related complication leading to adverse perinatal outcome so evaluating patients for high risk factors, early diagnosis, proper antenatal care, prompt treatment, regular follow up, and timely management thus can improve maternal and perinatal outcome.
\end{abstract}

Keywords: Adverse perinatal outcome, High risk pregnancy

\section{INTRODUCTION}

A high risk pregnancy is one in which mother, fetus or neonate is at increased risk of morbidity or mortality before or after delivery. ${ }^{1}$ Hence, a relatively small percentage of high risk obstetric population gives rise to a disproportionately high percentage of perinatal and maternal morbidity and mortality. ${ }^{2}$ It contributes to $80 \%$ of maternal mortality due to severe bleeding /hamorrhage (25\%), infections (15\%, unsafe abortions (13\%) eclampsia $(12 \%)$ obstructed lalor $(8 \%)$ and other direct causes $(8 \%)$. Indirect causes such as anaemia malaria, HIV/AIDS and cardiovascular diseases account for $20 \%$ of maternal mortality. ${ }^{3}$ The risk factors which include high risk pregnancy are pre-existing medical conditions eg. Hypertension, diabetes mellitus, HIV, maternal obesity, multiple births, pregnancy at both extremes of reproductive period and a number of biological and social factors such as age, parity, socioeconomic class, past obstetric history, occupation and psychosexual factors and nutritional status also influence the perinatal outcome. $^{4}$

High-risk pregnancy accounts for $75 \%$ of perinatal morbidity such as IUGR, preterm and low birth weight babies, respiratory distress syndrome, neonatal complications such as still births and early neonatal mortality. ${ }^{3}$ The perinatal mortality rate has often been used as an index of level of development of a country. Despite recent advances in modern obstetrics and neonatal care, India is still facing a high (46/1000) live births perinatal mortality rate; the perinatal outcome can 
be changed significantly by early detection and special intensive care to high risk pregnancies. ${ }^{5}$

Hence identification of patients at risk for these complicated pregnancies with poor outcome is fundamental to antenatal check-up.

\section{METHODS}

This is the prospective descriptive study from July 2017 to October 2017 conducted at Department of Obstetrics and Gynaecology L.L.R.M. Medical College, Meerut, Uttar Pradesh, India.

All antenatal patients attending the outpatient department and labour room were recruited after informed consent, those who fulfilled the inclusion criteria and were grouped in two categories.

- Group A: Included 86 High risk cases.

- Group B: Included 70 normal pregnancies with no associated risk factors The data comprised of two sections:

a) Demographic variables which included age, locality, educational status and socioeconomic status

b) Obstetric variables: Included gestational age, Parity, high risk conditions. Anemia, PIH, preterm labour, oligohydramnios, gestational diabetes mellitus, antepartum haemorrhage, previous LSCS.
Perinatal Outcome variables studied for the babies were birth weight, respiratory distress syndrome, Birth asphyxia, Neonatal hyperbilirubinemia. Prematurity, IUGR, Meconium Aspiration syndrome and neontal hypoglycemia, neonatal death and Apgar score within 1 min and 5 minutes after birth.

\section{RESULTS}

A total 86 high-risk pregnancy as study group and 70 normal pregnancies as control group with perinatal outcome were studied.

Among 86 study population majority belonged to age group of 21-29 years i.e. 62(72.09\%) with mean age being $25.1 \pm 4.5$ years. In control group also majority belong to age group of 21-29 years i.e. 57 patients $(81.42 \%)$, mean age being $24.6 \pm 4.2$ years.

Maximum number of women in both groups belonged to rural area i.e. $69.76 \%$ in study group and $68.57 \%$ in control group.

Patients belonging to high risk group and control group were mostly illiterate i.e. $58.13 \%$ and $57.14 \%$ respectively and most of the women in both groups belonged to low socioeconomic status $75.5 \%$ in high-risk group and $76.57 \%$ control group (Table 1).

Table 1: Distribution of demographic variables.

\begin{tabular}{|c|c|c|c|c|}
\hline Sr. No. & Demographic variables & Years & Group A $\quad(n=86)$ & Group B $(n=70)$ \\
\hline \multirow{3}{*}{1} & \multirow{3}{*}{ Age } & $18-20$ & $8(9.3 \%)$ & $4(5.7 \%)$ \\
\hline & & $21-29$ & $62(72.09 \%)$ & $57(81.4 \%)$ \\
\hline & & $>30$ & $16(18.60 \%)$ & $9(12.9 \%)$ \\
\hline \multirow{2}{*}{2} & \multirow{2}{*}{ Domicile } & Rural & $60(69.76 \%)$ & $48(68.57 \%)$ \\
\hline & & Urban & $26(30.23 \%)$ & $22(31.42 \%)$ \\
\hline \multirow{2}{*}{3} & \multirow{2}{*}{ Educational status } & Iliterate & $50(58 \%)$ & $40(57.1 \%)$ \\
\hline & & Literate & $36(42 \%)$ & 30 (42.9\%) \\
\hline \multirow{2}{*}{4} & \multirow{2}{*}{ Socioeconomic status } & Middle & $21(24.41 \%)$ & $15(21.4 \%)$ \\
\hline & & Low & $65(75.5 \%)$ & $55(78.6 \%)$ \\
\hline
\end{tabular}

Table 2: Distribution of obstetric variables.

\begin{tabular}{|c|c|c|c|c|c|c|c|}
\hline Sr. No. & Obstetric variables & Weeks & Gro & A $(n=86)$ & Gr & 70) & Mean \pm SD \\
\hline \multirow{3}{*}{1} & \multirow{3}{*}{$\begin{array}{l}\text { Gestational age (in } \\
\text { weeks) }\end{array}$} & $<37$ weeks & 13 & $15.1 \%$ & 5 & $7.1 \%$ & \\
\hline & & $37-40$ weeks & 62 & $72.1 \%$ & 55 & $78.6 \%$ & $38.20 \pm 0.79$ \\
\hline & & $>40$ weeks & 11 & $12.8 \%$ & 10 & $14.3 \%$ & $38.5 \pm 1.48$ \\
\hline \multirow{2}{*}{2} & \multirow{2}{*}{ Gravida } & Primi & 48 & $55.8 \%$ & 39 & $55.7 \%$ & \multirow{2}{*}{$38.20 \pm 0.79$} \\
\hline & & Multi & 38 & $44.2 \%$ & 31 & $44.3 \%$ & \\
\hline
\end{tabular}

Regarding gestational age majority of pregnancies belongs to 37-40 weeks of gestation with mean 38.2 \pm 0.79 weeks in high risk group and $38.5 \pm 1.48$ weeks in control group. Maximum women were primigravida in both groups $55.81 \%$ in study group and $55.71 \%$ in control group (Table 2).

The results compute that with regard to presence of high risk conditions in group A women. Majority of mothers 
were anemic $(55.81 \%), 13.95 \%$ had pregnancy induced hypertension, $2.32 \%$ had gestational diabetes mellitus (on diet control) and $2.32 \%$ had PIH. Preterm labour was present in $15.11 \%$ cases, $5.81 \%$ had oligohydramnios, $2.32 \%$ with antepartum haemorrhage and $2.32 \%$ were previous L.S.C.S (Table 3).

Regarding mode of delivery 37 women (43.02\%) in group A delivered by caesarean section as compared to $18(25.71 \%)$ in group B (Table 4$)$.

Table 3: High-risk conditions in study group.

\begin{tabular}{|lll|}
\hline High-risk condition & $\begin{array}{l}\text { No of women } \\
(\mathrm{n}=86)\end{array}$ & $\%$ \\
\hline Anaemia & 48 & 55.81 \\
\hline $\begin{array}{l}\text { Pregnancy induced } \\
\text { hypertension }\end{array}$ & 12 & 13.95 \\
\hline Pre term labour & 13 & 15.11 \\
\hline Pre eclampsia & 2 & 2.32 \\
\hline Oligohydramnios & 5 & 5.81 \\
\hline $\begin{array}{l}\text { Gestational diabetes on diet } \\
\text { control }\end{array}$ & 2 & 2.32 \\
\hline Ante partum haemorrhage & 2 & 2.32 \\
\hline Previous LSCS & 2 & 2.32 \\
\hline
\end{tabular}

Table 4: Mode of delivery.

\begin{tabular}{|lll|}
\hline Mode of delivery & $\begin{array}{l}\text { Group A, } \\
\text { n }(\%)\end{array}$ & $\begin{array}{l}\text { Group B, } \\
\text { n }(\%)\end{array}$ \\
\hline Caessarean section & $37(43.02 \%)$ & $18(25.71 \%)$ \\
\hline Normal delivery & $49(56.97 \%)$ & $52(74.28 \%)$ \\
\hline
\end{tabular}

Regarding birth weight $48(55.81 \%)$ and $23(32.85 \%)$ newborn of study and control group respectively delivered low birth weight $(<2.5 \mathrm{~kg}$ ) (Figure 1).

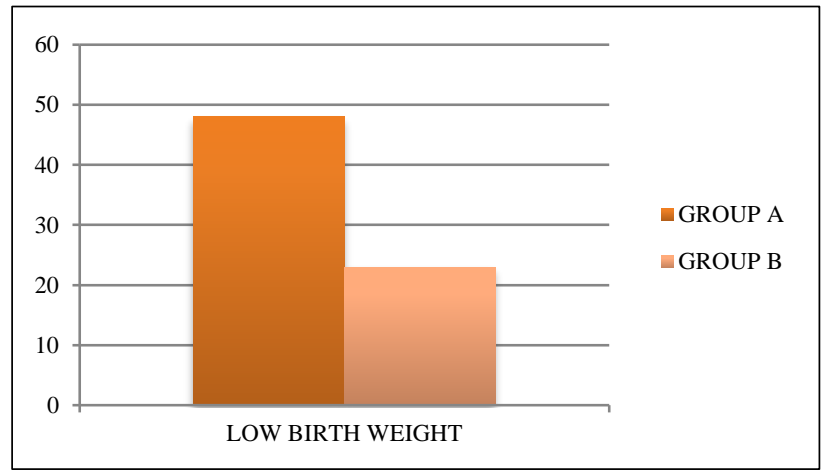

Figure 1: Comparison of low birth weight between study and control group.

Table 5: Comparative analysis of perinatal outcome between study group and control group.

\begin{tabular}{|c|c|c|c|c|c|}
\hline \multirow{2}{*}{ Perinatal outcome } & \multicolumn{2}{|l|}{ Study group A (86) } & \multicolumn{2}{|c|}{ Control group B (70) } & \multirow{2}{*}{$\begin{array}{l}\mathbf{P} \\
\text { value }\end{array}$} \\
\hline & No. & $\%$ & No. & $\%$ & \\
\hline Live birth & 76 & 88.37 & 69 & 98.57 & \multirow{2}{*}{$<0.01$} \\
\hline Still birth & 10 & 11.62 & 1 & 1.42 & \\
\hline Early Neonatal death & 4 & 4.65 & 1 & 1.42 & $<0.05$ \\
\hline Perinatal mortality & 14 & 16.27 & 2 & 2.85 & $<0.01$ \\
\hline Apgar score & Apgar score (1 min) & Apgar score (5 min) & Apgar score (1 min) & Apgar score $(5 \mathrm{~min}$ & \\
\hline No depression (7-10) & $58(67.44 \%)$ & $66(76.74 \%)$ & $62(88.57 \%)$ & $65(92.85 \%)$ & \\
\hline Mild depression (4-6) & $15(17.44 \%)$ & $9(10.46 \%)$ & $5(7.14 \%)$ & $3(4.28 \%)$ & $<0.05$ \\
\hline Severe depression $(<4)$ & $3(3.48 \%)$ & $2(2.32 \%)$ & 0 & 0 & $>0.05$ \\
\hline
\end{tabular}

Table 6: Comparative analysis of perinatal morbidity between study group and control group.

\begin{tabular}{|c|c|c|c|c|c|c|}
\hline \multirow{2}{*}{ Sr. No. } & \multirow{2}{*}{ Perinatal morbidity } & \multicolumn{2}{|c|}{ Study group (86) } & \multicolumn{2}{|c|}{ Control group (70) } & \multirow{2}{*}{ p value } \\
\hline & & No. & $\%$ & No. & $\%$ & \\
\hline 1 & Respiratory distress syndrome & 10 & 11.62 & 2 & 2.85 & $<0.01$ \\
\hline 2 & Birth Asphyxia & 4 & 4.65 & 2 & 2.85 & $>0.05$ \\
\hline 3 & Neonatal hyperbilirubinemica & 8 & 9.30 & - & - & \\
\hline 4 & Prematurity & 12 & 13.95 & 4 & 5.71 & $<0.01$ \\
\hline 5 & IUGR & 2 & 2.32 & 1 & 1.42 & $>0.05$ \\
\hline 6 & Meconium Aspiration syndrome & 4 & 4.65 & 3 & 4.28 & $>0.05$ \\
\hline \multirow[t]{2}{*}{7} & Neonatal hypoglycemia & 2 & 2 & - & - & \\
\hline & Total & 42 & 48.8 & 12 & 17 & $<0.01$ \\
\hline
\end{tabular}

In the study group neonatal death occurred in $4(4.65 \%)$ while only $1(1.42 \%)$ neonatal death occurred in control group. Stillbirths were more in high risk group compared to control group10 (11.62\%) vs. 1(1.42\%). Regarding Apgar score at $1 \mathrm{~min}$ mild depression was found in $17.44 \%$ and $7.14 \%$ newborns in high risk and control 
group respectively. 3 newborns in high risk group had severe depression $(\mathrm{AS}<4)$ while none of newborns in control group had severe depression. Regarding Apgar score at 5 min mild depression was found in $9(10.46 \%)$ and $3(4.28 \%)$ in high risk and control group respectively. 2 newborn in high risk group had severe depression while none in control group (Table 5).

A total $42(48.8 \%)$ babies in high risk group had perinatal morbidity which was in the form of prematurity, IUGR, respiratory distress syndrome and birth asphyxia compared to only $12(17 \%)$ neonate in control group ( $\mathrm{P}$ value<0.01) (Table 6).

\section{DISCUSSION}

In our study it is evident that the incidence of LBW was more in the study group as compared to low risk group. Near similar observations were reported by Dutta and Das, Samiya M, Bansal P. 5-7

In our study it is seen that the incidence of perinatal morbidity was more in high risk group. Prematurity was the most common perinatal morbidity $13.95 \%$ followed by respiratory distress syndrome $11.62 \%$ and neonatal hyperbilirubinemia $9.3 \%$ while in control group most common causes of perinatal morbodity was prematurity $5.71 \%$. Similar were findings of Jain et al where low risk group mothers had $50 \%$ lower incidence of high risk neonates $41.3 \%$ as compared to high risk group mothers who had $84.4 \%$ of high risk neonates. ${ }^{8}$

Maximum perinatal deaths 14 cases in the present study were in high risk group, with 2 in low risk group; this was in line with the findings observed by Jain $\mathrm{S}$ et al, where perinatal mortality rate was 198.8 and 614.5 in low and high risk groups respectably showing increased perinatal mortality with increased maternal high-risk score and also in the study by Bansal $\mathrm{P}$, the perinatal mortality was $2 \%$ in the high risk group with no mortality in control group. ${ }^{7,8}$

Apgar score was better in control group, 62 cases were observed in with score more than 7 and no cases had scoreless man. ${ }^{4}$ Similar results were observed by Bansal $\mathrm{P}$ and Vijayshree $\mathrm{M}$, wherein better Apgar score were observed in low risk groups. ${ }^{8,9}$ Similar results was observed by Jnaneswari K et al. ${ }^{10}$

\section{CONCLUSION}

This study emphasizes on pregnancy related complication leading to adverse perinatal outcome so evaluating patients for high risk factors, early diagnosis, proper antenatal care, prompt treatment, regular follow up, and timely management thus can improve maternal and perinatal outcome.

Funding: No funding sources

Conflict of interest: None declared

Ethical approval: The study was approved by the Institutional Ethics Committee

\section{REFERENCES}

1. Artal R. Overview of high-risk pregnancy, MSD manual professional Edition. 2015. Available at; http://www.msdmanuals.com/professional/gynecolog y-and-obstetrics/high-risk-pregnancy/overview-ofhigh- risk-pregnancy.

2. Krishnan V, Idris MZ, Srivastava VK, Bhushan V, Chandra MR. Scoring of high risk mothers and related outcome. Indian $\mathrm{J}$ Community Med. 1988:13(4):176-9.

3. Park K. Textbook of Preventive and Social Medicine, $21^{\text {st }}$ ed., Jabalpur: M/s Banarsidas Bhanot Publisher. 2011:513-24.

4. Shriver EK. National Institute of child health and human development. 2011. Available at: https://www.nichd.nih.gov/health. 11/04/2010.

5. Samiya M, Samina M. Identification of high-risk pregnancy by a scoring system and its correlation with perinatal outcome. Indian J Pract Dr. 2008:5(1).

6. Dutta S, Das XS. Identification of high risk mothers by a scoring system and it's correlation with perinatal outcome. J. Obstet Gynaecol India. 1990;40:181-90.

7. Bansal P, Verma D, Bansal A, Verma A. Prenatal risk score in high risk pregnancy cases and perinatal outcome:a study from South India. Int J Reprod Contracept Obstet Gynecol. 2016;5:3889-92.

8. Jain S, Anand S, Aherwar R. High risk scoring for prediction of pregnancy outcome: a prospective study. Int J Reprod Contracept Obstet Gynecol. 2014;3:516-22.

9. Vijayasree M. Increasing trend in caesarian section rate - the need for clinical evaluation of low risk and high risk indications. Int $\mathrm{J} \mathrm{Adv}$ Case Reports. 2015;2(9):557-66.

10. Jnaneswari K, Manjubala D. Perinatal outcome in high risk pregnancies. Int Res J Med Sci. 2016;4:1-4.

Cite this article as: Rani A, Karya U, Kumari S. Evaluation of perinatal outcome in high-risk pregnancy at tertiary care centre. Int J Reprod Contracept Obstet Gynecol 2019;8:2083-6. 